\title{
Across-countries genomic prediction using national breeding values or multitrait across-countries evaluation breeding values
}

\author{
M. Sallam, ${ }^{1 *} \odot$ H. Benhajali, ${ }^{1}$ S. Savoia, ${ }^{1} \odot$ D. J. de Koning, ${ }^{2} \odot$ and E. Strandberg ${ }^{2} \odot$ \\ ${ }^{1}$ Interbull Centre, Department of Animal Breeding and Genetics, Swedish University of Agricultural Science, Box 7023,75007 Uppsala, Sweden \\ ${ }^{2}$ Department of Animal Breeding and Genetics, Swedish University of Agricultural Science, Box 7023, 75007 Uppsala, Sweden
}

\section{ABSTRACT}

In across-country genomic predictions for dairy cattle, 2 kinds of bull information can be used as dependent variables. The first is estimated breeding value (EBV) from the national genetic evaluations, assuming genetic correlations between countries are less than 1. The second is EBV from multitrait across-countries evaluation (MACE), assuming genetic correlations between countries equal 1 . In the present study, the level of bias and reliability of a cross-countries genomic prediction using national EBV or MACE EBV as the dependent variable were investigated. Data from Brown Swiss Organizations joining the InterGenomics Service by Interbull Centre (Uppsala, Sweden) were used. National and MACE EBV of 3 traits (protein yield, cow conception rate, and calving interval) from 7, 5, and 4 countries, respectively, were used, resulting in 16 trait-country combinations. Genotypes for 45,473 SNP markers and deregressed (national or MACE) EBV of 7,490; 5,833; and 5,177 bulls were used in analysis of protein yield, cow conception rate, and calving interval, respectively. For most of trait-country combinations, the use of MACE EBV via single-trait approach resulted in less biased and more reliable across-countries genomic predictions. In case some of the MACE EBV might have been inflated, the resulting single-trait genomic predictions were inflated as well. For these specific cases, the use of national EBV via multitrait approach provided less bias and more reliable across-countries genomic predictions.

Key words: across-countries international genomic prediction evaluation, estimation of single nucleotide polymorphism effect, multitrait across-countries evaluation, national proof, Brown Swiss

Received June 15, 2021.

Accepted December 13, 2021.

*Corresponding author: mohammed.abdallah.sallam@slu.se

\section{INTRODUCTION}

In the animal breeding context, the main goal of statistics is to predict future performances using available information, phenotypic and pedigree data (classic BLUP; Henderson, 1984), in addition to genomic data (genomic prediction; Meuwissen et al., 2001; VanRaden, 2008; Legarra et al., 2014). Genomic prediction makes use of more data sources than traditional genetic prediction; thus, predictions are expected to be more reliable, especially for very young individuals that have no phenotypic records yet (VanRaden et al., 2009). Predicting future performance at an early stage of animal life is widely accepted as the main advantage of genomic prediction, which aims to decrease generations interval and speed up genetic gain. Consequently, genomic selection has been applied to dairy cattle breeding since 2009 in many countries (Hayes et al., 2009; Loberg and Dürr, 2009). Extension of genomic prediction from "within-country" to "across-countries" level is a point of great interest to (1) support decisions regarding import and export of bulls or semen across countries for breeding purposes (VanRaden and Sullivan, 2010), (2) improve genomic prediction reliabilities for small population breeds (e.g., Brown Swiss breed; Jorjani et al., 2011), and (3) estimate marker effects across countries while accounting for genotype by environment interactions $(\mathbf{G} \times \mathbf{E})$, which facilitates further identification of QTL that control a trait of interest.

The concept of prediction across countries is not new. Freeman (1983) proposed it well before the era of genomics, and Schaeffer (1994) implemented it based on pseudophenotype data of animals from several countries and connected through global pedigree, known as multiple-trait across-country evaluation (MACE). A few years later, MACE became a routine procedure by the Interbull Centre in Uppsala, Sweden (www.interbull .org).

Again, when aiming for genomic prediction or GWAS across countries, the unbiased estimation of SNP effects is a key challenge. The direct genomic value (DGV) of an individual for a specific trait is the sum of individual 
SNP genotypes multiplied by the estimated SNP effects of that trait (VanRaden, 2008; VanRaden et al., 2009; Liu et al., 2014). Thus, DGV and SNP effects could be viewed as 2 sides of the same coin. Both reliability and bias are 2 common metrics used to quantify the usefulness of prediction modeling approaches. Direct genomic values that are calculated from biased and less accurate marker effects will be biased and less accurate as well, and vice versa if the aim is to back-solving marker effects from DGV.

In across-country dairy cattle genomic evaluation, 2 kinds of information on bulls are available as dependent variables in estimation of SNP effects, and subsequently in prediction of DGV as follows: MACE EBV or separate national proofs (either EBV or PTA) from each country. The main difference is that MACE EBV are more accurate than national proofs. National proofs are EBV resulting from within-country genetic evaluations calculated through each country's national genetic evaluation system. The MACE EBV are obtained by combining national EBV of several countries in one multitrait analysis (MACE: Schaeffer, 1994) that Interbull Centre routinely runs. Consequently, 2 modeling approaches for across-countries estimation of SNP effects and DGV can be considered. The first is a multitrait approach (MT) where national EBV from several countries are directly combined using a multitrait genomic prediction method. The second is a single-trait approach (ST) where national EBV from several countries are combined in the conventional MACE and then the obtained MACE EBV are used on each country scale as a dependent variable in a single-trait genomic prediction method. The latter approach (ST) is used for across-countries genomic evaluation of both global Brown Swiss population and small-sized Holstein populations known as InterGenomics. InterGenomics is an international genotype-based genomic evaluation service provided by the Interbull Centre.

The objective of the present paper was to investigate bias and reliability of across-countries DGV predicted from ST or MT approaches, for high and low heritability traits in Brown Swiss dairy cattle.

\section{MATERIALS AND METHODS}

\section{Data}

In the ST, the EBV obtained from MACE (MACE run; April 2019) were used as the dependent variables after being deregressed using one-bull-at-a-time methods through equation [1] (Goddard, 1985) and equation [2] (VanRaden et al., 2009; Wiggans et al., 2011) as follows:

$$
\mathrm{DRP} 1_{\mathrm{MACE}}=\mathrm{EBV}_{\mathrm{MACE}^{*}} / \mathrm{REL}_{\mathrm{MACE}},
$$

where $\mathrm{DRP}=$ deregressed proofs, and $\mathrm{EBV}_{\mathrm{MACE}^{*}}$ is a standardized MACE EBV (by subtracting population mean and dividing by the standard deviation). Because we used standardized MACE EBV with zero mean, each $\mathrm{EBV}_{\mathrm{MACE}^{*}}$ was divided directly by its reliability $\left(\mathrm{REL}_{\mathrm{MACE}}\right)$ without adding a population mean that exists in the original formula of Goddard (1985). The second formula is as follows:

$$
\mathrm{DRP} 2_{\mathrm{MACE}}=\mathrm{PA}+\left(\mathrm{EBV}_{\mathrm{MACE}^{*}}-\mathrm{PA}\right) / \mathrm{REL}_{\text {Daughters }},
$$

where PA is the parent average using standardized $\mathrm{EBV}$, and $\mathrm{REL}_{\text {Daughters }}$ is the quantification of reliability (REL) contribution from daughters, calculated using daughter equivalent (DE) terms [(total DE - parent $\mathrm{DE}) /($ total $\mathrm{DE}-$ parent $\mathrm{DE}+1.0)]$. For derivation and explanation of DE terms, see VanRaden and Wiggans (1991). Parent averages (PA) were calculated by sire-dam method, where $\mathrm{PA}=0.5 \times(\mathrm{EBV}$ of sire + $\mathrm{EBV}$ of dam $)$ and PA reliability $=0.25 \times(\mathrm{REL}$ of sire + REL of dam). Although not published neither distributed, MACE evaluation estimates MACE EBV for bulls' dams as a function of the pedigree index.

In the MT, the national EBV (national proofs), submitted by Brown Swiss organizations as inputs for the Interbull MACE run of April 2019, were used as dependent variables after being deregressed by matrix deregression method (Sigurdsson and Banos, 1995; Jairath et al., 1998). Also, equation [2] was tested to deregress national EBV, except that PA were calculated by sire-maternal grand method because national proofs for dams were not available as follows: $\mathrm{PA}=(0.5$ $\times \mathrm{EBV}$ of sire $)+(0.25 \times \mathrm{EBV}$ of maternal grandsire $)$ and PA reliability $=0.25 \times[$ REL of sire $+(0.25 \times$ REL of maternal grandsire)].

Please note that equation [2] adjusts for PA, whereas equation [1] does not. In addition, in equation [2], the reliability used for weighting comes only from daughters, whereas in equation [1], the reliability comes from all relatives (daughters and parents).

After testing 2 deregression methods in each approach, equation [2] was selected to deregress MACE EBV in ST. The matrix deregression method was selected to deregress national proofs in MT, referred to as $\mathbf{D R P}_{\text {national }}$ in the present paper. When national EBV were deregressed by approximate deregression methods, extremely high variance values (possibly out of the maximum bound) were obtained especially for fertility traits (details not shown). With less information (i.e., 
Table 1. Trait-country combination definition and heritability

\begin{tabular}{llr}
\hline Trait-country & Definition & \\
\hline pro-A & Protein yield in first 3 lactations in country A & Heritability \\
pro-B & Protein yield in first 3 lactations in country B & 0.250 \\
pro-C & Protein yield in first 3 lactations in country C & 0.340 \\
pro-D & Protein yield in first 3 lactations in country D & 0.387 \\
pro-E & Protein yield in first 3 lactations in country E & 0.300 \\
pro-F & Protein yield in first 5 lactations in country F & 0.180 \\
pro-G & Protein yield in first 5 lactations in country G & 0.259 \\
cc1-Interbull definition & Lactating cow's ability to conceive (1), expressed as a rate trait. Traits such as conception rate \\
since August 2007 & CR) and nonreturn rate (NR; preferably NR56) will be considered for this trait group \\
cc1-A & NR = nonreturn rate after 56 d in cows (NRR) in country A, \% & 0.200 \\
cc1-B & NR = nonreturn rate after 56 d (NRR) in country B, \% & \\
cc1-C & NR = cow nonreturn rate after 56 d in country C, \% & \\
cc1-D & CR = cows conception rate (binary trait) in country D & \\
cc1-G & CR = conception rate (cow) in country G & \\
int-Interbull definition & Lactating cow's measurements of interval traits calving-conception, such as days open (DO) and \\
since August 2007 & calving interval (CI) & 0.027 \\
int-A & DO = days open in country A & 0.018 \\
int-C & DO = days open in country C & 0.016 \\
int-E & DP = daughter pregnancy rate in country E \\
int-G & DO = days open in country G & 0.045 \\
\hline
\end{tabular}

less reliability, as national EBV in the current study), the matrix deregression is a better choice despite greater computation costs. With more information (as MACE EBV in the current study), the approximate deregression methods with less computation costs could give results close to those of the matrix deregression method.

We studied 1 yield and 2 fertility traits as follows: protein yield (pro), cow conception rate (cc1), and calving interval (int) in 7, 5, and 4 countries, respectively, resulting in 16 trait-country combinations. Countries are coded A to G. Each trait-country combination is treated as a different trait and designated with trait and country code (e.g., pro-A for protein yield in country A). The more precise definition and heritability of each trait-country combination are summarized in Table 1. Genetic correlations between trait-country combinations were obtained from the Interbull MACE routine run of April 2019 for Brown Swiss (Table 2) and used only in the MT approach. Protein yield can be described as a high heritability trait with high genetic correlations between countries, whereas both cow

Table 2. Genetic correlations between trait-country combinations ${ }^{1}$

\begin{tabular}{|c|c|c|c|c|c|c|c|}
\hline pro & pro-A & pro-B & pro-C & pro-D & pro-E & pro-F & pro-G \\
\hline pro-A & 1 & & & & & & \\
\hline pro-B & 0.86 & 1 & & & & & \\
\hline pro-C & 0.86 & 0.92 & 1 & & & & \\
\hline pro-D & 0.84 & 0.84 & 0.81 & 1 & & & \\
\hline pro-E & 0.85 & 0.85 & 0.89 & 0.82 & 1 & & \\
\hline pro-F & 0.82 & 0.81 & 0.81 & 0.81 & 0.81 & 1 & \\
\hline pro-G & 0.89 & 0.83 & 0.82 & 0.86 & 0.83 & 0.82 & 1 \\
\hline $\mathrm{cc} 1$ & cc1-A & cc1-B & cc1-C & cc1-D & & & cc1-G \\
\hline cc1-A & 1 & & & & & & \\
\hline cc1-B & 0.79 & 1 & & & & & \\
\hline cc1-C & 0.79 & 0.95 & 1 & & & & \\
\hline cc1-D & 0.71 & 0.69 & 0.67 & 1 & & & \\
\hline cc1-G & 0.74 & 0.67 & 0.67 & 0.92 & & & 1 \\
\hline int & int-A & & int-C & & int-E & & int-G \\
\hline int-A & 1 & & & & & & \\
\hline int-C & 0.88 & & 1 & & & & \\
\hline int-E & 0.88 & & 0.93 & & 1 & & \\
\hline int-G & 0.9 & & 0.87 & & 0.89 & & 1 \\
\hline
\end{tabular}

${ }^{1}$ pro $=$ protein yield; cc1 $=$ cow conception rate; int $=$ calving interval. Countries are coded $\mathrm{A}$ to $\mathrm{G}$. 
Table 3. Number of reference and candidate bulls in single-trait approach (ST) and multitrait approach (MT) for each trait

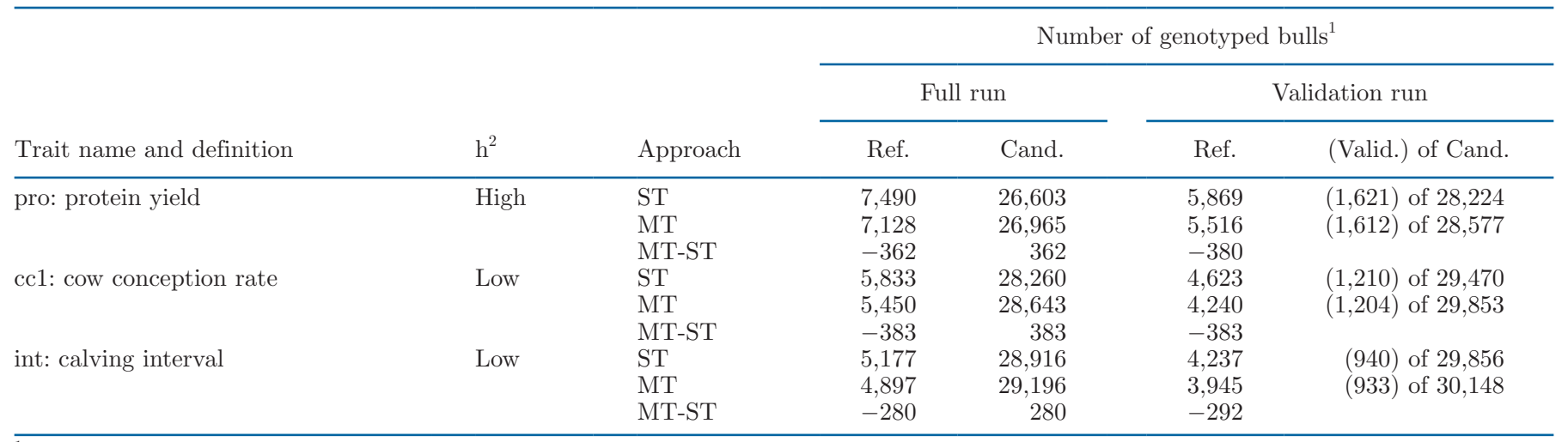

${ }^{1}$ Ref. = reference bulls; Cand. = candidate bulls; (Valid.) of Cand. = (validation bulls) out of candidate bulls.

conception rate and calving interval are low heritability traits. The genetic correlations for cow conception rate were a bit lower than genetic correlations for calving interval (Table 2).

Genotypes of 34,093 bulls were obtained from the IG routine run of April 2019 for Brown Swiss breed. Each genotyped bull was assigned as a reference or a candidate bull. A bull was assigned to be a reference bull only if the bull had been genotyped and had available breeding value obtained by MACE (for ST analysis) or national evaluation (for MT analysis). Bulls were assigned to be a candidate if the bull had only been genotyped. The number of reference bulls in ST approach was larger than in MT approach, as shown in Table 3. In both ST and MT approaches, the same pedigree of 91,874 animals have been used in both approaches.

\section{Genotype Processing}

Countries participating in IG share genotypes derived from different SNP chips and densities. The shared genotypes have been combined using a reference map containing 55,172 SNPs. In the first stage, the SNPs present in the shared genotypes but missing from the common reference map were set to missing. Duplicate genotypes (within and across countries) were removed from the reference map, keeping only the genotype with fewer missing SNPs. The consistency of SNPs across sire-son parentage was checked on both autosomes and sex-chromosome. A sire-son conflict was defined as the condition where sire and son are homozygous for alternative alleles of a given SNP. The pedigree-based relationships were removed (i.e., sire set to be missing) for the sire-son that showed conflicts for more than 600 SNPs. In addition, the SNPs that showed conflicts for more than 200 sire-son parentages were set to be missing SNPs for all genotyped individuals. As routinely done by Interbull Centre, genotypes for missing mark- ers were imputed using FindHap Software (Van Raden, 2015). The imputation step used a static reference map of 55,172 SNPs. The SNPs that were missing in preliminary quality checks were probably not imputed due to lack of information. After the imputation step, these missing SNPs were removed from the further analysis in case they were missing in more than $10 \%$ of genotyped animals. Moreover, only SNPs with genotypes frequencies of both homozygotes and heterozygous greater than zero were included in the evaluation.

\section{Statistical Approach to Compute DGV}

From a computational aspect, the main difference between ST and MT approaches is that the latter fits $\mathrm{DRP}_{\text {national }}$ and makes use of genetic correlations between traits (trait-country combinations) estimated in the MACE workflow by the Interbull Centre. Thus, MT fits all trait-country combinations simultaneously. On the other hand, ST with DRP2 $2_{\mathrm{MACE}}$ fits only 1 trait-country combination per run and assumes that genetic correlations between countries are equal to 1 because genetic correlations of MACE EBV on a specific country scale equal 1 . This means we needed $n$ runs by ST approach to perform evaluations for $\mathrm{n}$ traitcountry combinations, but only 1 run by MT approach to perform evaluations for the same $\mathrm{n}$ trait-country combinations. The MT genomic prediction with DRP$2_{\text {MACE }}$ was not suggested to avoid double counting of the information because, in such a case, the information of between-countries genetic correlations would be used twice, once in MACE analysis to obtain MACE EBV and once again in MT genomic prediction. The ST genomic prediction with $\mathrm{DRP}_{\text {national }}$ did not provide across-countries predictions and thus was not considered in the current study.

Both ST and MT statistical computations in the current study were based on the multistep genomic pre- 
diction approach (VanRaden, 2008; VanRaden et al., 2009). The first step is as follows:

(1) The SNP marker effects are estimated from reference bulls via "Bayes-A SNP model," which also fits a residual polygenic effect. The equation is as follows:

$$
\mathbf{y}=\mu+\mathbf{Z g}+\mathbf{W u}+\mathbf{e},
$$

where $\mathbf{y}$ is an $n \times 1$ vector of $\mathrm{DRP} 2_{\mathrm{MACE}}$ in $\mathrm{ST}$ or $\mathrm{DRP}_{\text {national }}$ in $\mathrm{MT}$, where $n$ is the number of reference individuals in each approach; $\mu$ is a scalar of general mean in ST or a vector of general means in MT; $\mathbf{Z}$ is an $n \times m$ design matrix that relates deregressed EBV to SNP effects and contains allele codes $(0,1$, and 2 for aa, Aa, and AA, respectively) of $n$ reference bulls minus twice the allele frequency; for $m$ SNP markers, $m$ equals 45,473 in both approaches. Base allele frequencies were used in the present study, estimated separately by method of Gengler et al. (2007). Additionally, $\mathbf{g}$ is an $m \times 1$ vector of marker effects in ST or $m \times t$ matrix in MT where $t$ is the number of trait-country combinations; $\mathbf{W}$ is $p \times 1$ design matrix that relates records to animals where $p$ equals the number of animals in the pedigree or $p \times t$ design matrix in $\mathrm{MT} ; \mathbf{u}$ is $1 \times p$ vector of polygenic effects in ST or $t \times p$ matrix in MT; $\mathbf{e}$ is an $n \times 1$ vector of residuals that contains the adjusted reliability of $\mathrm{DRP} 2_{\mathrm{MACE}}$ in ST and $\mathrm{DRP} \mathrm{P}_{\text {national }}$ in MT.

Both approaches assume that marker effects explain $90 \%$ of genetic variance in the dependent variable $(\mathbf{y})$, whereas the polygenic effect explains the rest. Both approaches assume that each marker has an effect, and these effects are assumed to have a heavy-tailed prior distribution referred to as "Bayes A prior" analogous to that proposed by (Meuwissen et al., 2001), which makes the estimation of SNP effects a nonlinear estimation. Polygenic variance is the $10 \%$ of genetic variance explained by pedigree relationships. Both approaches fit the unknown parent groups when solving for the polygenic effect to account for selection in the data. Equations of base allele frequencies, marker effects, and polygenic effects have been solved by blending firstand second-order Jacobi iteration on data (VanRaden, 2008), as implemented on densemap.f90 package (Fortran program written by Paul VanRaden, version 2006, Animal Improvement Programs Lab, USDA). Both matrix deregression calculations and genetic correlations between countries have been obtained from
Interbull Centre's routine workflow, which were based on software created and developed by Interbull Centre geneticists. The second step is as follows:

(2) Direct genomic values are the sum of SNP genotypes multiplied by the estimated marker effects for reference and candidate bulls. This is expressed as follows:

$$
\mathbf{D G V}=\mathbf{Z}_{\mathrm{all}} \hat{\mathbf{g}}
$$

where $\mathbf{Z}_{\text {all }}$ is as $\mathbf{Z}$ is defined above, except $n$ here equals the number of references and candidates, and $\hat{\mathbf{g}}$ are estimates of $\mathbf{g}$ as defined above.

\section{Calculation of Prediction Bias and Reliability}

The DGV from each approach for each trait-country combination were compared based on their prediction bias and associated observed validation reliabilities. A group of reference bulls that were born after 2007 were selected as validation bulls. Validation bulls are those bulls that have genotypes and pseudophenotypes (deregressed EBV) in the full run and have only genotypes in the validation run. Validation bulls were excluded from the reference bulls, resulting in the numbers shown in Table 3 . Both $\mathrm{DRP}$ national $_{\text {and }} \mathrm{DRP} 2_{\mathrm{MACE}}$ were regressed on the corresponding DGV predicted from MT and ST validation runs, respectively, as follows:

$$
\mathbf{D R P}=\mathrm{b}_{0}+\mathrm{b}_{1} \mathbf{x}_{\mathbf{p}}+\mathbf{e},
$$

where DRP is $\mathrm{DRP}_{\text {national }}$ in MT or $\mathrm{DRP} 2_{\mathrm{MACE}}$ in $\mathrm{ST}$, $b_{0}$ is the intercept, $b_{1}$ is the linear regression coefficient indicating bias of predictions, $\mathbf{x}_{\mathrm{p}}$ is the predicted DGV from MT or ST validation runs, and $\mathbf{e}$ is the residual term. Before running such regression, DRP2 $2_{\mathrm{MACE}}$, ST DGV, DRP ${ }_{\text {national }}$, and MT DGV were back-transformed to the original trait-country scale. Thus, regression results across approaches have the same scale. The reliability of ST DGV was measured as the squared correlation coefficient $\left(\mathrm{r}^{2}\right)$ between ST validation run DGV and DRP $2_{\mathrm{MACE}}$. The reliability of MT DGV was measured as $\mathrm{r}^{2}$ between the MT validation run DGV and $\mathrm{DRP}_{\text {national }}$.

\section{RESULTS}

\section{Prediction Variances}

Theoretically, reliability is the proportion of the variance of true breeding values that is explained by the variance in EBV (Goddard, 1985). Assuming covariance 
between true and EBV equals the variance of $\mathrm{EBV}$, the higher the variance of the DGV, the higher the reliability of DGV prediction will be. The difference between standard deviations of ST DGV and MT DGV was calculated for all bulls, and for reference and candidate bulls separately, for each trait-country combination (Table 4). The ST approach resulted in a higher DGV standard deviation than the MT approach for all traitcountry combinations except in a few cases where DGV standard deviation differences were in favor of the MT approach (Table 4). The approach that resulted in a higher DGV variance could be classified as the more accurate approach, unless this higher variance was due to overestimation bias. Correlations between ST and MT DGV for candidate animals were, on average 0.98, 0.90, and 0.80 for protein yield, cow conception rate, and calving interval, respectively (Table 4). This indicated the ranking of candidate individuals by either ST or MT were very similar in high heritable traits but quite different in low heritable traits in the present study.

\section{Prediction Bias and Reliability}

Bias $\left(b_{1}\right)$ and reliability $\left(\mathrm{r}^{2}\right)$ were calculated for ST validation bulls with national proofs. The validation bulls with national proofs represented the common validation bulls in both $\mathrm{ST}$ and MT validation runs. Therefore, ST validation results could be compared with the corresponding MT validation results [Tables 5,6 , and 7 for protein yield, cow conception rate, and calving interval, respectively].

Regression coefficients $\left(b_{1}\right)$ for protein yield from $\mathrm{ST}$ indicated an overestimation (inflation), especially in country $\mathrm{E}\left(\mathrm{b}_{1}=0.47\right)$, country $\mathrm{F}\left(\mathrm{b}_{1}=0.79\right)$, and country $\mathrm{G}\left(\mathrm{b}_{1}=0.78\right)$, whereas regression coefficients from MT indicated unbiased predictions with $b_{1}$ very close to 1 . Furthermore, the validation reliabilities $\left(\mathrm{r}^{2}\right)$ were in favor of MT predictions for all trait-country combinations regarding protein yield (Table 5). For fertility traits (Tables 6 and 7) within each approach, some trait-country combinations showed overestimation and others were unbiased with $b_{1}$ very close to 1. In general, across approaches, ST prediction showed better $b_{1}$ and $r^{2}$ than MT approach for fertility traits (Tables 6 and 7).

Given that MACE EBV are input for ST DGV predictions, and to assess the ability of past MACE solutions to predict the current national evaluations, we regressed national proofs of April 2019 on MACE EBV of April 2016, April 2017, and April 2018, for validation bulls, as shown for protein yield (Table 8), cow conception rate (Table 9), and calving interval (Table 10). Considering $b_{1}=0.90$ as overestimation threshold, results indicated that past MACE EBV overestimated the corresponding current national EBV for protein yield, cow conception rate, and calving interval as shown in Tables 8, 9, and 10, respectively, where cases below the overestimation threshold are shown.

\section{DISCUSSION}

The aim of the present study was to investigate the reliability and bias of 2 approaches (ST and MT) used for across-countries genomic prediction in Brown Swiss dairy cattle. For the computation of across-countries genomic predictions, several methods have been developed depending on the information approved to be shared by countries participating in across-countries genomic evaluations. The genomic MACE method (VanRaden and Sullivan, 2010) is applied when countries agree on sharing their genomically enhanced EBV, as is the case for the global Holstein population. Multistep methods (VanRaden and Sullivan, 2010) are applied when countries agree on sharing genotypes, but not raw phenotypes, as is the case for the global Brown Swiss population. The single-step method (Legarra et al., 2014) can be applied when countries agree to share both genotypes and raw phenotypes, as in international beef evaluation, Interbeef (Bonifazi et al., 2020). It is worth it to mention one of reviewer's suggestions for further research to combine deregressed national EBV from each country with the genotypes from most countries using multitrait-single-step method. The so-called SNP-MACE method (Jighly et al., 2019) has recently been suggested when countries agree on sharing their SNP marker effects solutions. As mentioned earlier, the current situation in Brown Swiss dairy cattle is that countries share genotypes, but not phenotypes. Consequently, deregressed EBV are routinely used as an alternative to real phenotypes via multistep genomic prediction methods (VanRaden, 2008; VanRaden et al., 2009), such as $\mathrm{DRP}_{\text {national }}$ in MT and $\mathrm{DRP} 2_{\mathrm{MACE}}$ in case of ST.

The MACE EBV are not only more accurate than national proofs, but also MACE EBV implicitly account for genetic correlations across countries (i.e., $\mathrm{G}$ $\times \mathrm{E})$. Thus, this latter property of MACE EBV via ST approach is theoretically suggesting safe modeling of heterogeneous SNP effects across countries. Even for ST runs in each trait-county scale, the results can be considered "across countries genomic predictions" because the ST reference population fits all domestic and foreign bulls that have MACE EBV on the same trait-county scale. This may be the primary rationale behind selecting the ST approach to be routinely applied to carry out genomic evaluation for the global Brown Swiss population by Interbull Centre since 2011, known as InterGenomics (Jorjani et al., 2011). However, 
Table 4. Direct genomic value (DGV) SD and correlations between DGV from multitrait approach (MT) and single-trait approach (ST) in all trait-country combinations for all, reference (Ref.), and candidate (Cand.) bulls, in addition to candidates born after the year 2007

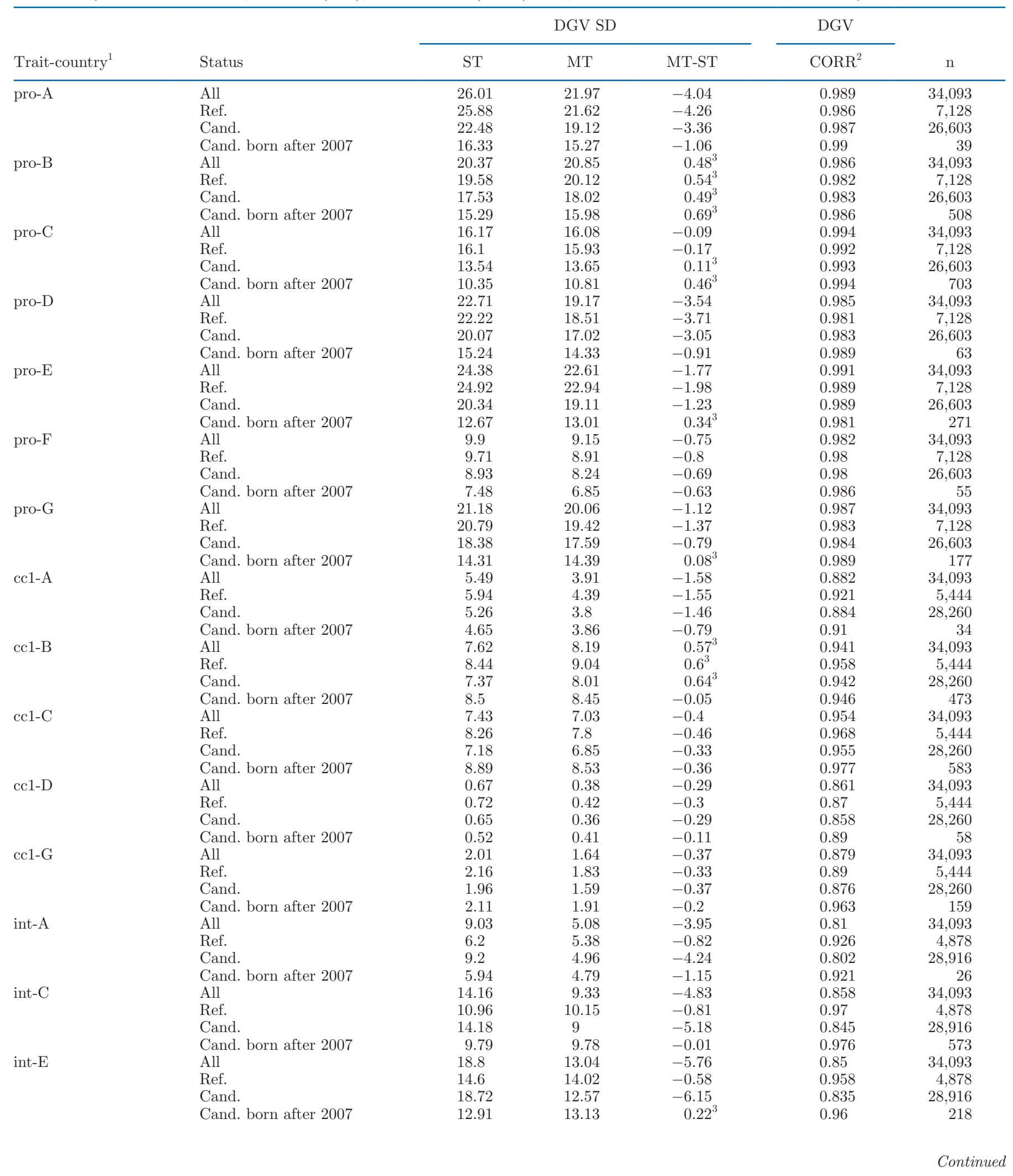


Table 4 (Continued). Direct genomic value (DGV) SD and correlations between DGV from multitrait approach (MT) and single-trait approach (ST) in all trait-country combinations for all, reference (Ref.), and candidate (Cand.) bulls, in addition to candidates born after the year 2007

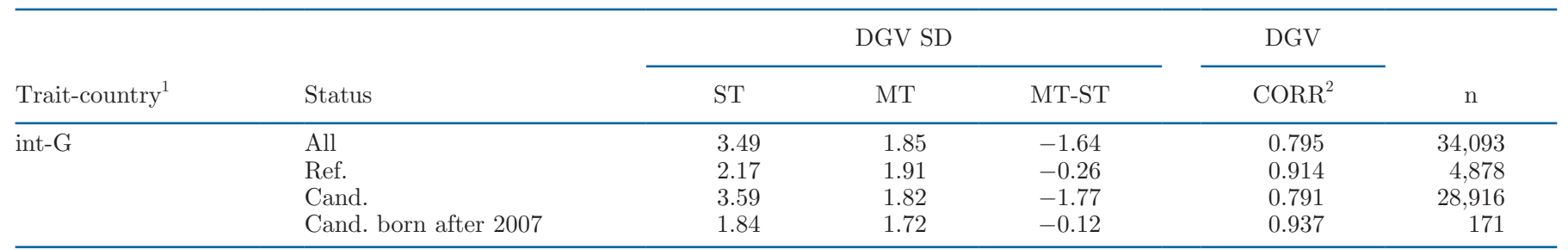

${ }^{1}$ pro $=$ protein yield; $c c 1=$ cow conception rate; int = calving interval. Countries are coded A to $\mathrm{G}$.

${ }^{2} \mathrm{CORR}=$ correlation.

${ }^{3}$ The cases where MT DGV SD exceeded ST DGV.

Table 5. Regression of deregressed EBV on direct genomic values (DGV) obtained from the corresponding validations runs, for validation bulls that have national proofs, for protein yield (pro)-country combinations (countries are labels A-G)

\begin{tabular}{|c|c|c|c|c|c|c|c|c|}
\hline Trait-country & $\begin{array}{l}\text { DGV } \\
\text { SD }\end{array}$ & $\begin{array}{l}\text { Deregressed } \\
\text { EBV SD }\end{array}$ & Correlation & $\mathrm{b}_{0}$ & $\mathrm{~b}_{1}$ & Residual & $\mathrm{r}^{2}$ & $\begin{array}{l}\text { Validation } \\
\text { bulls (n) }\end{array}$ \\
\hline \multicolumn{9}{|c|}{$\begin{array}{l}\text { Regression of deregressed MACE EBV } \\
\text { on DGV of ST validation } \text { run }^{1}\end{array}$} \\
\hline pro-B & 15.23 & 19.60 & 0.70 & 4.05 & 0.90 & 13.96 & 0.49 & 508 \\
\hline pro-C & 10.56 & 13.08 & 0.67 & 3.11 & 0.83 & 9.70 & 0.45 & 703 \\
\hline pro-D & 13.79 & 18.72 & 0.64 & -2.60 & 0.86 & 14.58 & 0.40 & 63 \\
\hline pro-G & 13.81 & 18.75 & 0.58 & 1.20 & 0.78 & 15.35 & 0.33 & 177 \\
\hline \multicolumn{9}{|c|}{$\begin{array}{l}\text { Regression of deregressed national EBV } \\
\text { on DGV of MT validation } \text { run }^{2}\end{array}$} \\
\hline pro-A & 13.42 & 23.85 & 0.85 & -11.57 & 1.51 & 12.66 & 0.73 & 39 \\
\hline pro-B & 15.98 & 19.27 & 0.83 & 2.81 & 1.00 & 10.81 & 0.69 & 508 \\
\hline pro-C & 11.28 & 14.11 & 0.79 & 1.36 & 0.99 & 8.63 & 0.63 & 703 \\
\hline pro-D & 13.29 & 19.47 & 0.88 & -6.08 & 1.28 & 9.50 & 0.77 & 63 \\
\hline
\end{tabular}

${ }^{1}$ Deregressed by equation [2]; MACE $=$ multitrait across-countries evaluation; ST = single-trait approach.

${ }^{2}$ Deregressed by matrix method; MT = multitrait approach.

Table 6. Regression of deregressed EBV on direct genomic values (DGV) obtained from the corresponding validations runs, for validation bulls that have national proofs, for cow conception rate (cc1)-country combinations (countries are labeled A-G)

\begin{tabular}{|c|c|c|c|c|c|c|c|c|}
\hline Trait-country & $\begin{array}{l}\text { DGV } \\
\text { SD }\end{array}$ & $\begin{array}{c}\text { Deregressed } \\
\text { EBV SD }\end{array}$ & Correlation & $\mathrm{b}_{0}$ & $\mathrm{~b}_{1}$ & Residual & $r^{2}$ & $\begin{array}{l}\text { Validation } \\
\text { bulls (n) }\end{array}$ \\
\hline \multicolumn{9}{|l|}{ Regression of deregressed MACE } \\
\hline $\mathrm{cc} 1-\mathrm{B}$ & 7.56 & 22.70 & 0.48 & -46.21 & 1.43 & 19.97 & 0.23 & 473 \\
\hline cc1-C & 8.12 & 16.28 & 0.57 & -13.30 & 1.15 & 13.36 & 0.33 & 583 \\
\hline cc1-D & 0.49 & 0.87 & 0.50 & 0.23 & 0.90 & 0.76 & 0.25 & 58 \\
\hline cc1-A & 3.65 & 13.87 & 0.03 & 92.10 & 0.09 & 14.08 & 0.00 & 34 \\
\hline cc1-B & 8.10 & 26.69 & 0.25 & 12.48 & 0.82 & 25.86 & 0.06 & 473 \\
\hline cc1-C & 8.01 & 18.25 & 0.42 & 6.68 & 0.95 & 16.62 & 0.17 & 583 \\
\hline cc1-D & 0.35 & 1.14 & 0.30 & 0.37 & 0.98 & 1.10 & 0.09 & 50 \\
\hline cc1-G & 1.71 & 5.94 & 0.32 & 0.12 & 1.12 & 5.64 & 0.10 & 159 \\
\hline
\end{tabular}

${ }^{1}$ Deregressed by equation [2]; MACE $=$ multitrait across-countries evaluation; $\mathrm{ST}=$ single-trait approach.

${ }^{2}$ Deregressed by matrix method; MT $=$ multitrait approach. 
Table 7. Regression of deregressed EBV on direct genomic values (DGV) obtained from the corresponding validations runs, for validation bulls that have national proofs, for calving interval (int)-country combinations (countries are labeled A-G)

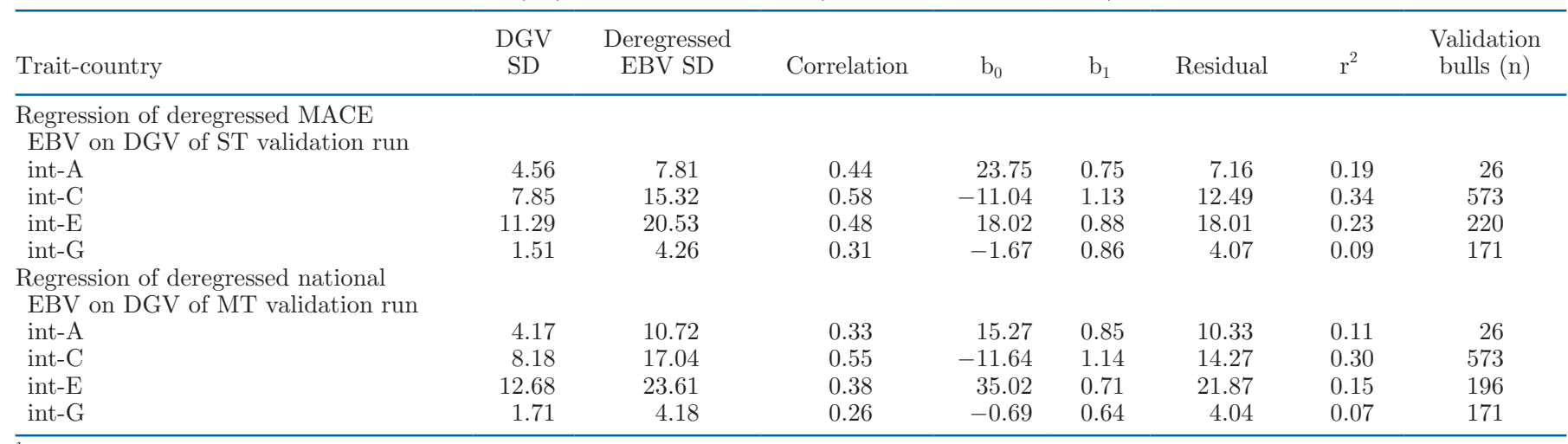

${ }^{1}$ Deregressed by equation [2]; MACE $=$ multitrait across-countries evaluation; ST $=$ single-trait approach.

${ }^{2}$ Deregressed by matrix method; MT = multitrait approach.

properties of MACE EBV may be violated (Weigel et al., 1996; Doormaal et al., 1999; Gengler et al., 2000; Miglior et al., 2002; Ducrocq et al., 2003; Nicolazzi et al., 2011). For example, Nicolazzi et al. (2011) showed that observed correlations between MACE EBV and national EBV might be highly different from the ex- pected correlations. Therefore, national proofs via MT (with genetic correlations between countries less than 1) could be an alternative approach of explicit modeling of heterogeneous SNP effects across countries.

Although the present study focused on acrosscountries genomic predictions, it is also relevant to

Table 8. Assessment of the ability of past multitrait across-countries evaluation (MACE) solutions to predict the current national evaluations, for group (n) out of common validation bulls in single-trait (ST) and multitrait (MT) approaches, for each of protein yield (pro)-country combinations (countries are labeled $\mathrm{A}-\mathrm{G}$ )

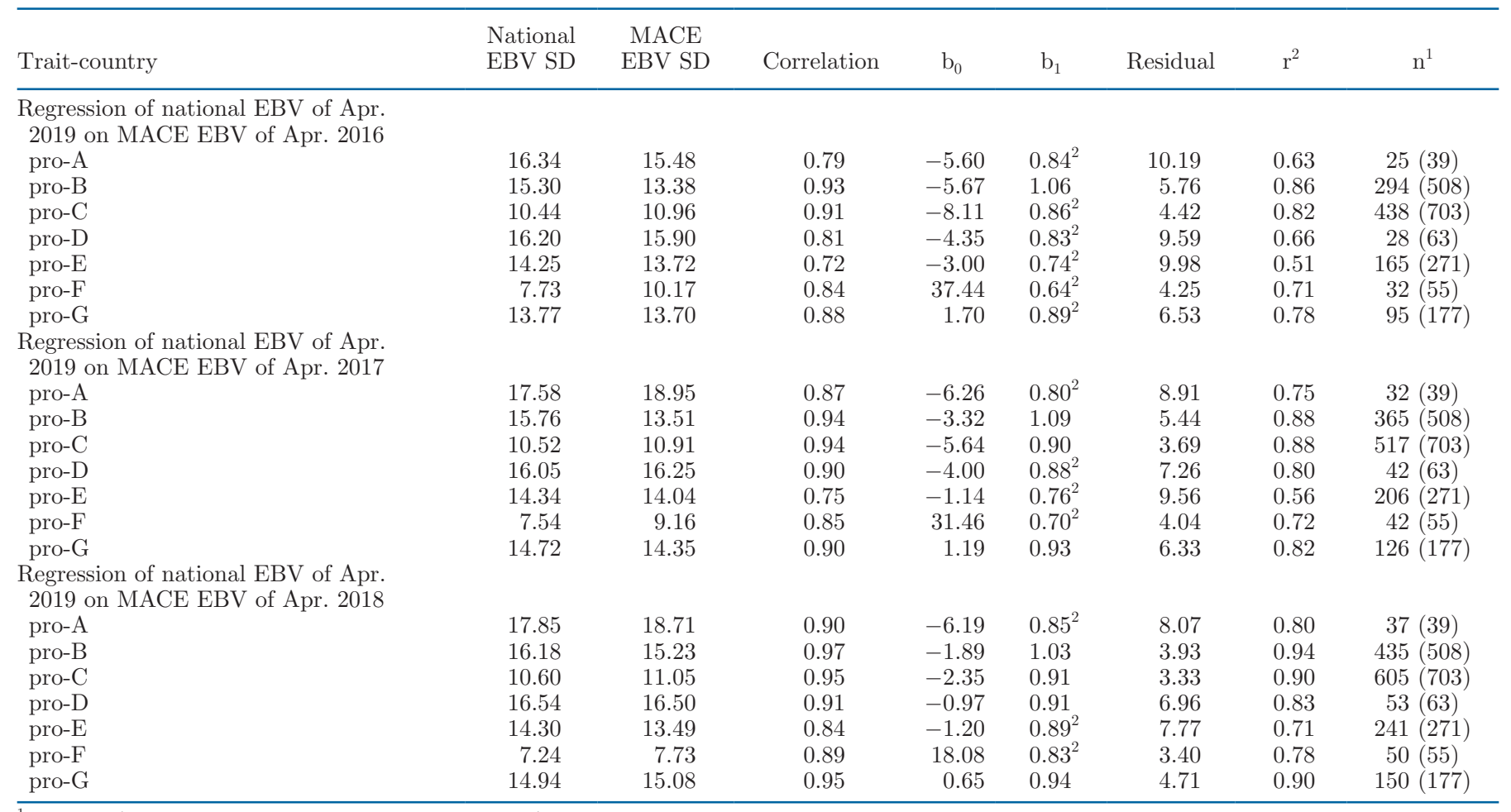

${ }^{1} \mathrm{n}$ out of (common validation bulls in ST and MT).

${ }^{2}$ The cases where $\mathrm{b}_{1}<0.90$. 
Table 9. Assessment of the ability of past multitrait across-countries evaluation (MACE) solutions to predict the current national evaluations, for group (n) out of common validation bulls in single-trait (ST) and multitrait (MT) approaches, for each of cow conception rate (cc1)-country combinations (countries are labeled $\mathrm{A}-\mathrm{G}$ )

\begin{tabular}{|c|c|c|c|c|c|c|c|c|}
\hline Trait-country & $\begin{array}{l}\text { National } \\
\text { EBV SD }\end{array}$ & $\begin{array}{c}\text { MACE } \\
\text { EBV SD }\end{array}$ & Correlation & $\mathrm{b}_{0}$ & $\mathrm{~b}_{1}$ & Residual & $r^{2}$ & $\mathrm{n}^{1}$ \\
\hline \multicolumn{9}{|l|}{ Regression of national EBV of Apr. } \\
\hline cc1-B & 8.81 & 8.23 & 0.88 & 5.08 & 0.94 & 4.27 & 0.77 & $257(473)$ \\
\hline cc1-C & 9.44 & 8.63 & 0.90 & 2.39 & 0.99 & 4.04 & 0.82 & $350(583)$ \\
\hline cc1-D & 0.54 & 0.44 & 0.75 & -0.08 & 0.92 & 0.37 & 0.56 & $19(58)$ \\
\hline \multicolumn{9}{|l|}{ Regression of national EBV of Apr. } \\
\hline cc1-A & 5.30 & 3.85 & 0.69 & 5.72 & 0.94 & 3.94 & 0.47 & $26(34)$ \\
\hline cc1-B & 8.53 & 8.43 & 0.91 & 6.81 & 0.92 & 3.47 & 0.83 & $332(473)$ \\
\hline cc1-C & 9.37 & 8.87 & 0.93 & 2.92 & 0.98 & 3.47 & 0.86 & $434(583)$ \\
\hline cc1-D & 0.53 & 0.47 & 0.77 & -0.06 & $0.87^{2}$ & 0.35 & 0.59 & $27(58)$ \\
\hline cc1-G & 2.23 & 2.12 & 0.92 & -0.43 & 0.97 & 0.89 & 0.84 & 104 \\
\hline \multicolumn{9}{|l|}{$\begin{array}{l}\text { Regression of national EBV of Apr. } \\
2019 \text { on MACE EBV of Apr. } 2018\end{array}$} \\
\hline cc1-G & 2.18 & 2.27 & 0.94 & -0.27 & 0.91 & 0.72 & 0.89 & 133 (159) \\
\hline
\end{tabular}

${ }^{1} \mathrm{n}$ out of (common validation bulls in ST and MT).

${ }^{2}$ The cases where $\mathrm{b}_{1}<0.90$.

similar cases within countries where conventional MT methods are used to obtain within-country EBV followed by ST genomic prediction. An alternative could be conventional ST data analysis methods to obtain within-country EBV followed by MT genomic prediction within country.

\section{Deregression of National Proofs and MACE EBV}

Several deregression methods have been reported and could be classified into the following 2 main categories: matrix deregression and approximate deregression. Some studies refer to approximate deregressions as

Table 10. Assessment of the ability of past multitrait across-countries evaluation (MACE) solutions to predict the current national evaluations, for group (n) out of common validation bulls in single-trait (ST) and multitrait (MT) approaches, for each calving interval (int)-country combinations (countries are labeled $\mathrm{A}-\mathrm{G}$ )

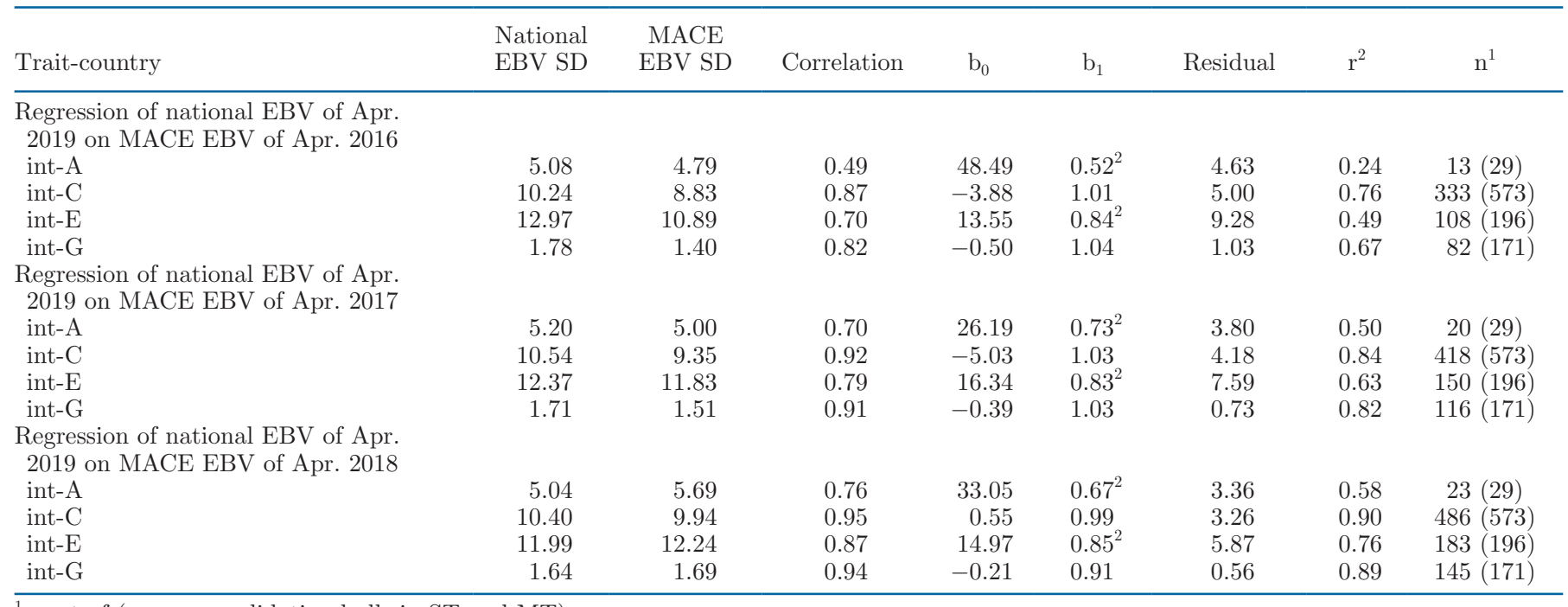

${ }^{1} \mathrm{n}$ out of (common validation bulls in ST and MT).

${ }^{2}$ The cases where $\mathrm{b}_{1}<0.90$. 
"one-bull-at-a-time deregressions." A detailed explanation of these methods and how to calculate them are reviewed in Calus et al. (2016). Matrix deregression method requires an inversion part (Jairath et al., 1998) of the mixed model coefficient matrix that becomes extremely large for large pedigree files. The MACE EBV matrix deregression using the exact pedigree used during the MACE process is still a challenging task and computationally demanding, especially when it comes to routine practices. Compared with the MACE pedigree, national evaluation pedigrees are somehow smaller and, consequently, national EBV matrix deregressions could be less computationally demanding and routinely applied within the workflow of the MACE process (Sigurdsson and Banos, 1995; Jairath et al., 1998) at Interbull Centre. The MACE EBV in the current study are approximately deregressed based on equations [1] and [2]. We noted that equation [1] resulted in more varied deregressed MACE EBV (more variance) than outcomes of the equation [2] (details not shown). In addition, DGV predicted from MACE EBV deregressed by equation [2] were less biased than DGV predicted from the simplest deregression equation [1] in almost all trait-country combinations tested in the ST approach (Supplemental Table S1; https://doi.org/10.6084/m9 .figshare.18857390.v3, Sallam et al., 2022). Therefore, the approximate deregression method via equation [2] has been used in the current study for the deregression of MACE EBV.

\section{ST and MT Prediction Variances}

Estimation of marker effects in the current study was based on the Bayesian framework using "Bayes A" prior. As the prior used in both ST and MT was the same, the DGV standard deviation (SD) differences are supposed to be due to the SD differences in input data (y), which are in almost all trait-country combination in favor of ST. This is because ST input data (y) comes from the MACE process based on data of about 11 countries analyzed simultaneously by a multitrait framework, whereas the MT input data (y) comes from national evaluations based on only single-country data. Therefore, less information is available in input data (y) of the current MT, and consequently, input SD differences are in favor of ST approach (Table 11).

Even though the current MT included information in a similar way as MACE, the number of countries participating within the current MT (range; 4-7) was much smaller than those participating in MACE $(\sim 11$ for Brown Swiss breed). If the number of countries participating in MACE and the current MT were the same, the DGV SD differences between MT and ST would be expected to be close to zero. Another reason for DGV SD being higher for ST approach is the reference population's size, which is larger in ST than that in MT (Table 3). Larger reference population could be viewed as a source of more input variances at the level of genomic (SNP) information or dependent variable (y) information.

In a few cases, the DGV SD differences were in favor of MT as in the following trait-country combinations: pro-B, pro-C (candidate bulls only), pro-E (only candidate bulls born after 2007), cc1-B, and int-E (only candidate bulls born after 2007) as shown in Table 4. Even if using only a few cases, investigating them helps to understand both approaches. They are cases where MT DGV variances exceeded ST DGV variances despite that ST input data (y) variances exceeded MT input data (y). Some reasons are suggested to explain such findings. First, MT DGV could have biased overestimation as cases in cow conception rate (cc1) and calving interval (int) (see regression coefficients $b_{1}$ in Tables 6-7). Otherwise, in cases where MT DGV were not overestimated, ST inputs (MACE EBV) might not have fully accounted for the $\mathrm{G} \times \mathrm{E}$ property, probably due to inflation of some MACE solutions (i.e., inflation of MACE solutions might violate $\mathrm{G} \times \mathrm{E}$ property of MACE EBV). Subsequently, for such specific cases, ST inputs via genetic correlations equal 1, and they did not fully model heterogeneous SNP effects across countries as MT inputs (national proofs) were done via genetic correlations less than 1 .

\section{ST and MT Prediction Bias and Reliability}

We aimed to validate DGV from each approach (ST and $\mathrm{MT}$ ) against its corresponding input (DRP2 $2_{\mathrm{MACE}}$, and $\mathrm{DRP}_{\text {national }}$, respectively). However, the correlation between DRP2 $2_{\mathrm{MACE}}$ and DRP ${ }_{\text {national }}$ could be only moderate in some cases of fertility traits (Supplemental Table S2, https://doi.org/10.6084/m9.figshare.18857390 .v3, Sallam et al., 2022). That is why we revalidated DGV from each approach (ST and MT) against the same variable, DRP $2_{\mathrm{MACE}}$. Validation results showed that $\mathrm{r}^{2}$ and $\mathrm{b}_{1}$ improved by validating MT DGV against $\mathrm{DRP} 2_{\mathrm{MACE}}$ (i.e., MT DGV are more correlated with $\mathrm{DRP} 2_{\mathrm{MACE}}$ than to $\left.\mathrm{DRP} \mathrm{P}_{\text {national }}\right)$. Detailed results are reported in Supplemental Tables S3 to S5 (https:// doi.org/10.6084/m9.figshare.18857390.v3, Sallam et al., 2022). For example, in protein yield, MT DGV r ${ }^{2}$ increased by 9 points in average (range: $1-17$ ). The results of MT and ST DGV validation using DRP $2_{\mathrm{MACE}}$ as a reference variable showed a pattern very similar to results of MT and ST DGV validation using $\mathrm{DRP}_{\text {national }}$ and DRP $2_{\mathrm{MACE}}$, respectively. We will discuss the latter results because some interesting improvements were made based on them. 
The ST DGV are estimated from MACE EBV that are derived from national proofs. Several validation tests (Boichard et al., 1995; Lidauer et al., 2005) are routinely applied on national proofs by Interbull Centre before accepting them into the MACE process. On the other hand, no validation tests are applied to MACE EBV before using them for genomic prediction. The inflation of ST DGV (Tables 5-7) may be explained by inflation of MACE solutions (Tables 8-10), as shown through regressing recent national proofs on past MACE EBV solutions. For instance, inflation of MACE EBV for protein yield (Table 8 ) in country E $\left(\mathrm{b}_{1}=0.74,0.76,0.89\right)$ and country $\mathrm{F}\left(\mathrm{b}_{1}=0.64,0.70\right.$, $0.83)$ may explain the inflation of ST DGV of protein yield (Table 5$)$ in country $\mathrm{E}\left(\mathrm{b}_{1}=0.47\right)$ and country $\mathrm{F}$ $\left(b_{1}=0.79\right)$. Contrary to ST DGV inflation for protein

Table 11. Inputs [EBV SD, reliability (REL) mean], deregressed EBV SD, and outputs (direct genomic value; DGV) for common reference bulls in single-trait approach (ST) and multitrait approach (MT)

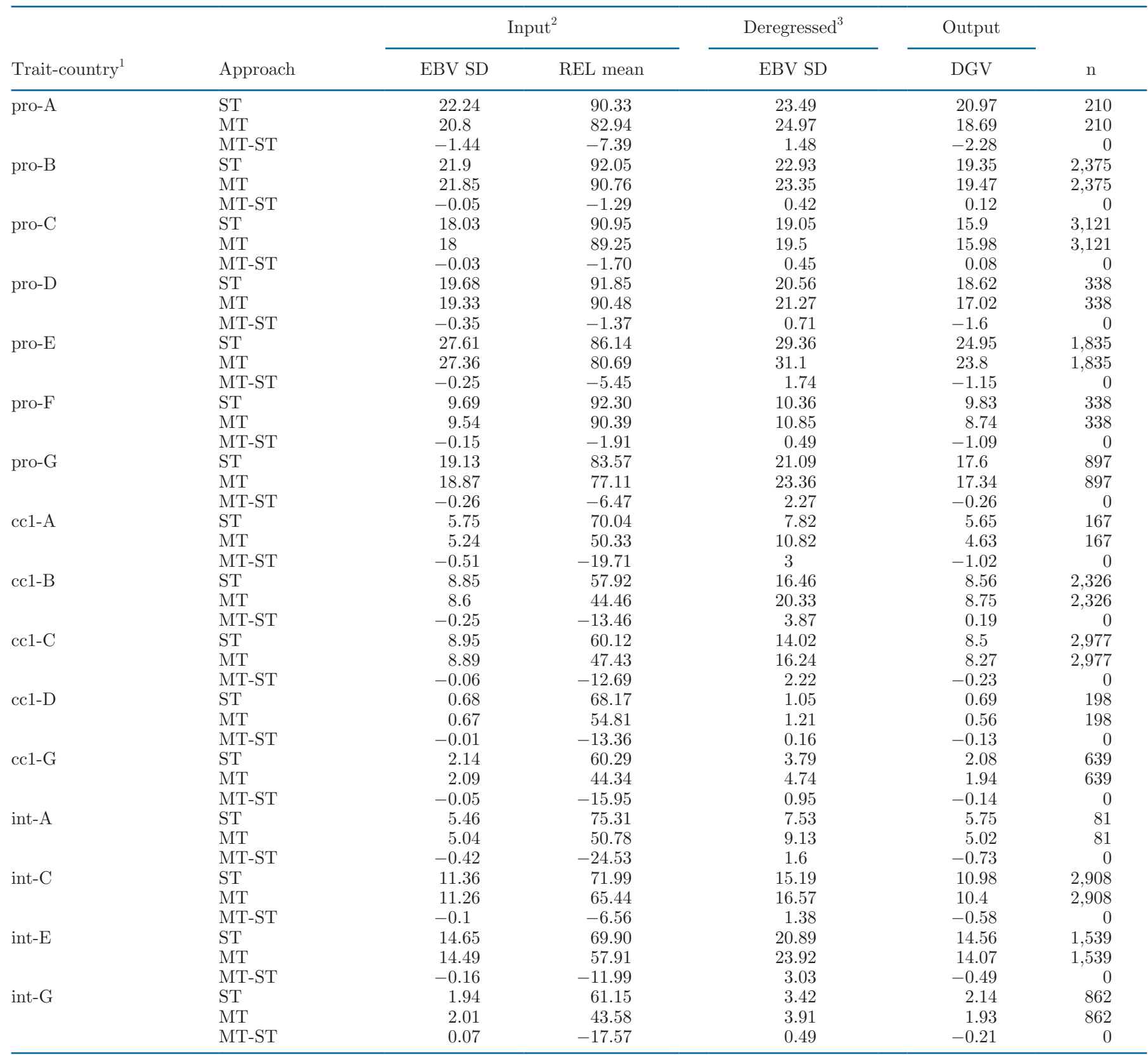

${ }^{1}$ pro $=$ protein yield $; \mathrm{cc} 1=$ cow conception rate; int $=$ calving interval. Countries are coded A to $\mathrm{G}$.

${ }^{2} \mathrm{EBV}$ are multitrait across-countries evaluation EBV in ST and national proofs in MT.

${ }^{3}$ Deregressed EBV; deregression by equation [2] in ST and by matrix method in MT. 
yield, the MT DGV indicated approximately unbiased and more reliable predictions (Table 5). Thus, the MT approach outperformed ST in protein yield trait in the current study. Reliabilities of protein yield DGV (Table 5) from MT, but not ST, are very similar to reliabilities of multicountry genomic prediction reported in Table 3 of VanRaden and Sullivan (2010). Genotypes were simulated for 9 countries by VanRaden and Sullivan (2010), whereas only 7 out of these 9 countries provided us with real genotypes in the present study. The current study suggested that reliabilities obtained from simulated data were very similar to those from the current MT approach.

When it comes to fertility traits, MT DGV showed more bias and less reliability than ST DGV. One potential reason for inflations in MT DGV could be the inclusion of imported bulls in the MT reference populations. These imported bulls do not have enough recorded daughters in the importing country and genetically might belong to another population. We tried to decrease the inflation of MT DGV by excluding imported bulls from the reference population in case they had fewer than 215 recorded daughters (equivalent to $\sim 0.75$ reliability in fertility traits) in the importing country. After applying this condition on MT reference bulls of only 1 country in cow conception rate, which was cc1-D, we observed that regression coefficient $\left(b_{1}\right)$ changed from $0.37,0.64,0.81,0.65$, and 0.78 to 0.09 , $0.82,0.95,0.95$, and 1.12, respectively, in country A, B, $\mathrm{C}, \mathrm{D}$, and $\mathrm{G}$. This indicated improvement in $\mathrm{b}_{1}$ for all of these countries except country A, where the opposite occurred. Please note that $b_{1}$ values of MT in Table 6 are these $b_{1}$ values after this condition was applied. For calving interval trait, after excluding all imported bulls with fewer than 125 daughter records from MT reference population, the DGV inflations were improved a little but still observed as shown by $b_{1}$ values of $\mathrm{MT}$ in Table 7. These findings agree with previous studies that recommend the exclusion of low-reliability bulls from reference bulls to avoid bias of genomic predictions (Liu et al., 2014, 2011). Therefore, excluding all bulls with fewer daughter records regardless of imported or nonimported status may improve MT DGV inflation. However, we think that the exclusion process should be carefully done because it may come at the expense of reference population size, especially for low heritability traits that generally require large reference population for good reliabilities.

In the present study, the use of MACE EBV (via ST) for across-countries prediction of SNP effects and DGV was shown to provide higher prediction variances (Table 4) than the use of national proofs. This indicated the importance of the MACE combining information from multiple countries. However, in case some of the
MACE EBV were inflated, the resulting ST genomic predictions were expected to be inflated as well (as in protein yield; Table 5). For these specific cases, we recommend using national EBV instead of MACE EBV for across-countries genomic prediction. In addition, we recommend checking for the inflation of MACE solutions before their use in genomic evaluations or QTL analysis.

\section{CONCLUSIONS}

For across-countries genomic prediction, the use of MACE EBV via a ST resulted in across-countries genomic predictions that were less biased and more reliable. Alternatively, use of national EBV via a MT could result in more reliable and less biased acrosscountries genomic predictions when MACE EBV have some inflations, which is the reason that MACE EBV may not fully account for genotype by environment (countries) interactions. In addition, the present study showed that some improvement in prediction bias (inflation or overestimation) could be achieved by selecting a proper deregression procedure in approaches of multistep genomic prediction and excluding bulls of low reliability from reference populations.

\section{ACKNOWLEDGMENTS}

The authors thank the Brown Swiss community for providing the data and the Interbull Steering Committee. The authors also thank the Interbull Centre team in Uppsala, Sweden. Two anonymous reviewers are also thanked for their thoughtful comments and review of the manuscript. This study received no external funding. The authors have not stated any conflicts of interest.

\section{REFERENCES}

Boichard, D., B. Bonaiti, A. Barbat, and S. Mattalia. 1995. Three methods to validate the estimation of genetic trend for dairy cattle. J. Dairy Sci. 78:431-437. https://doi.org/10.3168/jds.S0022 $-0302(95) 76652-8$.

Bonifazi, R., J. Vandenplas, J. Ten Napel, A. Michenet, A. Cromie, R. Veerkamp, and M. Calus. 2020. International single-step genomic evaluations in beef cattle. Page 579 in 71st Annual Meeting of the European Federation of Animal Science. EAAP.

Calus, M. P. L., J. Vandenplas, J. ten Napel, and R. F. Veerkamp. 2016. Validation of simultaneous deregression of cow and bull breeding values and derivation of appropriate weights. J. Dairy Sci. 99:6403-6419. https://doi.org/10.3168/jds.2016-11028.

Doormaal, B. J. V., G. J. Kistemaker, and P. G. Sullivan. 1999. Heterogeneous variances of Canadian bull EBVs over time. Interbull Bull. 22:141.

Ducrocq, V., I. Delaunay, D. Boichard, and S. Mattalia. 2003. A general approach for international genetic evaluations robust to inconsistencies of genetic trends in national evaluations. Interbull Bull. 30:101. 
Freeman, A. E. 1983. Results of Holstein breed comparisons in European countries. Page 90B97 in Proc. 1st Int. Holstein Conf. Symp.

Gengler, N., T. Dusseldorf, G. R. Wiggans, J. R. Wright, and T. Druet. 2000. Joint estimation of variances and effects in the US Jersey type evaluation system. Interbull Bull. 26:34.

Gengler, N., P. Mayeres, and M. Szydlowski. 2007. A simple method to approximate gene content in large pedigree populations: Application to the myostatin gene in dual-purpose Belgian Blue cattle. Animal 1:21-28. https://doi.org/10.1017/S1751731107392628.

Goddard, M. 1985. A method of comparing sires evaluated in different countries. Livest. Prod. Sci. 13:321-331. https://doi.org/10.1016/ 0301-6226(85)90024-7.

Hayes, B. J., P. J. Bowman, A. J. Chamberlain, and M. E. Goddard. 2009. Invited review: Genomic selection in dairy cattle: Progress and challenges. J. Dairy Sci. 92:433-443. https://doi.org/10.3168/ jds.2008-1646.

Henderson, C. R. 1984. Applications of Linear Models in Animal Breeding. University of Guelph.

Jairath, L., J. C. M. Dekkers, L. R. Schaeffer, Z. Liu, E. B. Burnside, and B. Kolstad. 1998. Genetic evaluation for herd life in Canada. J. Dairy Sci. 81:550-562. https://doi.org/10.3168/jds.S0022 -0302(98)75607-3.

Jighly, A., H. Benhajali, Z. Liu, and M. Goddard. 2019. SNPMace A meta-analysis to estimate SNP effects across countries. Pages 107-115 in Proc. 2019 Interbull Meeting.

Jorjani, H., J. Jakobsen, M. Nilforooshan, E. Hjerpe, B. Zumbach, V. Palucci, and J. Dürr. 2011. Genomic evaluation of BSW populations, InterGenomics: Results and deliverables. Interbull Bull. 43:5-8.

Legarra, A., O. F. Christensen, I. Aguilar, and I. Misztal. 2014. Single step, a general approach for genomic selection. Livest. Sci. 166:5465. https://doi.org/10.1016/j.livsci.2014.04.029.

Lidauer, M., E. A. Mäntysaari, J. Pedersen, and I. Strandén. 2005. Model validation using individual daughter deviations - statistical power. Interbull Bull. 33:195.

Liu, Z., M. E. Goddard, F. Reinhardt, and R. Reents. 2014. A singlestep genomic model with direct estimation of marker effects. J. Dairy Sci. 97:5833-5850. https://doi.org/10.3168/jds.2014-7924.

Liu, Z., F. R. Seefried, F. Reinhardt, S. Rensing, G. Thaller, and R. Reents. 2011. Impacts of both reference population size and inclusion of a residual polygenic effect on the accuracy of genomic prediction. Genet. Sel. Evol. 43:19. https://doi.org/10.1186/1297 $-9686-43-19$

Loberg, A., and J. Dürr. 2009. Interbull survey on the use of genomic information. Interbull Bull. 39:3.

Meuwissen, T. H. E., B. J. Hayes, and M. E. Goddard. 2001. Prediction of total genetic value using genome-wide dense marker maps. Genetics 157:1819-1829. https://doi.org/10.1093/genetics/157.4 1819 .

Miglior, F., P. G. Sullivan, and B. J. V. Doormaal. 2002. Preliminary analysis of mendelian sampling terms for genetic evaluation validation. Interbull Bull. 29:183.
Nicolazzi, E. L., F. Forabosco, and W. F. Fikse. 2011. Assessment of the value of international genetic evaluations for yield in predicting domestic breeding values for foreign Holstein bulls. J. Dairy Sci. 94:2601-2612. https://doi.org/10.3168/jds.2010-3558.

Sallam, M., H. Benhajali, S. Savoia, D. J. de Koning, and E. Strandberg. 2022. Sallam et al._2022_supplemental_tables.docx. figshare. Journal contribution. https://doi.org/https://doi.org/10 .6084/m9.figshare.18857390.v3.

Schaeffer, L. R. 1994. Multiple-country comparison of dairy sires. J. Dairy Sci. 77:2671-2678. https://doi.org/10.3168/jds.S0022 -0302(94)77209-X.

Sigurdsson, A., and G. Banos. 1995. Dependent variables in international sire evaluations. Acta Agric. Scand. A Anim. Sci. 45:209217. https://doi.org/10.1080/09064709509413079.

Van Raden, P. M. 2015. findhap.f90, Find haplotypes and impute genotypes using multiple chip sets and sequence data. Accessed Feb. 24, 2015. http://aipl.arsusda.gov/software/findhap/.

VanRaden, P. M. 2008. Efficient methods to compute genomic predictions. J. Dairy Sci. 91:4414-4423. https://doi.org/10.3168/jds .2007-0980.

VanRaden, P. M., and P. G. Sullivan. 2010. International genomic evaluation methods for dairy cattle. Genet. Sel. Evol. 42:7. https: //doi.org/10.1186/1297-9686-42-7.

VanRaden, P. M., C. P. Van Tassell, G. R. Wiggans, T. S. Sonstegard, R. D. Schnabel, J. F. Taylor, and F. S. Schenkel. 2009. Invited review: Reliability of genomic predictions for North American Holstein bulls. J. Dairy Sci. 92:16-24. https://doi.org/10.3168/jds .2008-1514.

VanRaden, P. M., and G. R. Wiggans. 1991. Derivation, calculation, and use of national animal model information. J. Dairy Sci. 74:2737-2746. https://doi.org/10.3168/jds.S0022-0302(91)78453 -1 .

Weigel, K. A., G. Banos, and A. Sigurdsson. 1996. International sire evaluations and conversions in upgrading populations with changing means and variances. Interbull Bull. 14:21.

Wiggans, G. R., T. A. Cooper, P. M. VanRaden, and J. B. Cole. 2011. Technical note: Adjustment of traditional cow evaluations to improve accuracy of genomic predictions. J. Dairy Sci. 94:6188-6193. https://doi.org/10.3168/jds.2011-4481.

\section{ORCIDS}

M. Sallam @ (ttps://orcid.org/0000-0002-4485-7626

S. Savoia $\odot$ https://orcid.org/0000-0003-3537-0768

D. J. de Koning () https://orcid.org/0000-0001-6343-8155

E. Strandberg (๑) https://orcid.org/0000-0001-5154-8146 